The frequency of RP attacks was detected more than once a day in 44 (42\%) patients. In $73 \%$ of cases, RP did not show signs of deep digital ischemia. Digital ulcers (active) were observed in $13(12.3 \%)$ patients, fractures in a finger area - 23 (21.9\%), digital scars - 15 (14.2\%), phalange amputations - 7 (6.6\%)

Conclusion: Patients with RD and secondary RP most often have SSC (55\%), less often - SLE (17\%), RA (6\%), DM (3\%). In SSc and SLE patients, Raynaud's reddening of fingers to cold is less common than in other RD. In SSc, two-/threephase changes of fingers color in the cold are more frequent than single-phase changes. In SLE, fingers turn blue in the cold more often than in SSc.

References:

[1] Prete M, Fatone MC, Favoino E, Perosa F. Raynaud's phenomenon: from molecular pathogenesis to therapy. Autoimmun Rev 2014;13:655-67.

[2] Linnemann B, Erbe M. Raynaud's phenomenon - assessment and differential diagnoses. Vasa 2015;44:166-77.

[3] Heidrich H, Helmis J, Fahrig C, Hovelmann R, Martini N. Clinical characteristics of primary, secondary and suspected secondary Raynaud's syndrome and diagnostic transition in the long-term follow-up. A retrospective study in 900 patients.Vasa 2008;37 (Suppl. 73):3-25.

[4] Pavlov-Dolijanovic S, Damjanov NS, VujasinovicStupar NZ, Radunovic GL, Stojanovic RM, Babic D. Late appearance and exacerbation of primary Raynaud's phenomenon attacks can predict future development of connective tissue disease: a retrospective chart review of 3035 patients. Rheumatollnt 2013;33:921-6.

Acknowledgments: Professor LP. Anan'eva, Professor RT. Alekperov

Disclosure of Interests: Ilshat Gaisin Speakers bureau: Boehringer Ingelheim, KRKA, Berlin-Chemie Menarini, Sanofi, Zukhra Bagautdinova: None declared, Rosa Valeeva: None declared, Nikolay Maximov Speakers bureau: Pfizer, KRKA, Oxana Desinova: None declared, Rushana Shayakhmetova: None declared, Irina Sabelnikova: None declared, Anna Tukmacheva: None declared, Larisa Gibadullina: None declared, Natalya Burlaeva: None declared, Elena Agareva: None declared, Yulia Ochkurova: None declared, Tatyana Bragina: None declared, Ksenia Alexandrova: None declared, Elvira Reutova: None declared

DOI: 10.1136/annrheumdis-2020-eular.1930

\section{AB0577 ENDOTHELIAL DYSFUNCTION AND ATHEROSCLEROSIS IN SYSTEMIC SCLEROSIS: A MULTIPARAMETRIC ANALYSIS USING IMAGING TECHNIQUE AND LABORATORY MARKERS OF INFLAMMATION AND VASCULAR FUNCTION: SCLERODERMA CV RISK STUDY}

N. Garg ${ }^{1}$, A. Syngle ${ }^{2,3}$, D. Gera ${ }^{1}$, S. Kaur ${ }^{2} .{ }^{1}$ Chitkara University, Chitkara College of Pharmacy, Rajpura, Punjab, India; ${ }^{2}$ Cardio Rheuma Division, Healing Touch City Clinic, Chandigarh, India; ${ }^{3}$ Fortis Multispecialiy Hospital, Internal Medicine and Rheumatology, Mohali, India

Background: Systemic sclerosis (SSc) patients have an increased risk for atherosclerotic cardiovascular disease (CVD), possibly mediated by inflammatory and fibrotic mechanisms ${ }^{1}$. However, pathogenesis of accelerated atherosclerosis in SSc remains to be elucidated. Endothelial dysfunction is the key initial event in atherosclerosis. Predictors for rapid evolution of cardiovascular complications would be highly desirable for $\mathrm{CV}$ risk stratification. This study aims to assess endothelial function and atherosclerosis in SSc, in context of markers of inflammation and vascular function in SSc patients.

Objectives: To assess endothelial function and atherosclerosis in SSc in context of markers of inflammation and vascular function in SSc patients.

Methods: A cross-sectional study was performed in 20 SSc patients meeting the 2013 European League Against Rheumatism (EULAR) and American College of Rheumatology (ACR) classification criteria and 18 healthy controls matched for age and sex. Flow-mediated dilatation (FMD) assessed by AngioDefender and CIMT measured ultrasonographically. Disease-specific measures included: Disease duration, Modified Rodnan Skin Score (mRSS), EUSTAR activity score in SSc. We also assayed markers of inflammation, including C-reactive protein (CRP), erythrocyte sedimentation rate (ESR), proinflammatory cytokines (interleukin IL-1, IL-6, and IL-17), and endothelial dysfunction including lipids, serum nitrite and TBARS (marker of oxidative stress). Quality of life measured by Scleroderma Health Assessment Questionnaire (SHAQ)

Results: FMD is significantly lower in SSc patients compared with controls $(6.13 \pm 0.35 \%$ vs. $9.12 \pm 0.25 \%, p \leq 0.05)$. CIMT is significantly higher in SSc patients compared with controls $(0.071 \pm 0.04 \mathrm{~cm}$ vs. $0.035 \pm 0.02 \mathrm{~cm} p \leq 0.05)$. Compared with controls, SSc patients had significantly $(p \leq 0.05)$ elevated mRSS, EUSTAR score, ESR, CRP, IL-1, IL-6, IL-17, nitrite, TBARS and SHAQ whereas HDL levels are significantly reduced in SSc compared with controls $(p \leq 0.05)$. In SSc, FMD inversely correlated with EUSTAR score, mRSS, IL-6 (Fig. 1A), serum nitrite (Fig. 1B), TBARS (Fig. 1C) and CIMT (Fig. 1D). CIMT positively correlated with age (Fig. 2A), disease duration, CRP (Fig. 2B) and IL-17 (Fig. 2C) and inversely correlated with HDL (Fig. 2D) $(p<0.05)$.

Conclusion: In the present study, FMD and CIMT are impaired in SSc, indicating endothelial dysfunction and accelerated atherosclerosis, respectively. EUSTAR score, mRSS, IL-6, serum nitrite, CIMT and TBARS predicted endothelial dysfunction. Age, disease duration, CRP, IL-17, HDL and impaired FMD predicted accelerated atherosclerosis. SSc-related inflammatory mechanisms (IL-6, IL-17) and markers of vascular function (CRP, serum nitrite and TBARS) may all be involved in the development of vascular disease in SSc. Cytokine-triggered inflammation mediated by nitrite and TBARS is associated with endothelial dys function and accelerated atherosclerosis in SSc. These markers would possibly serve as predictors of endothelial dysfunction and atherosclerosis and more importantly therapeutic targets to prevent premature atherosclerosis and cardiovascular disease in SSc.

\section{References:}

[1] Pagkopoulou E, Poutakidou M, Garyfallos A, Kitas G, Dimitroulas T. Cardiovascular risk in systemic sclerosis: Micro- and Macro-vascular involvement. Indian Journal of Rheumatology 2017;12:S211-7.
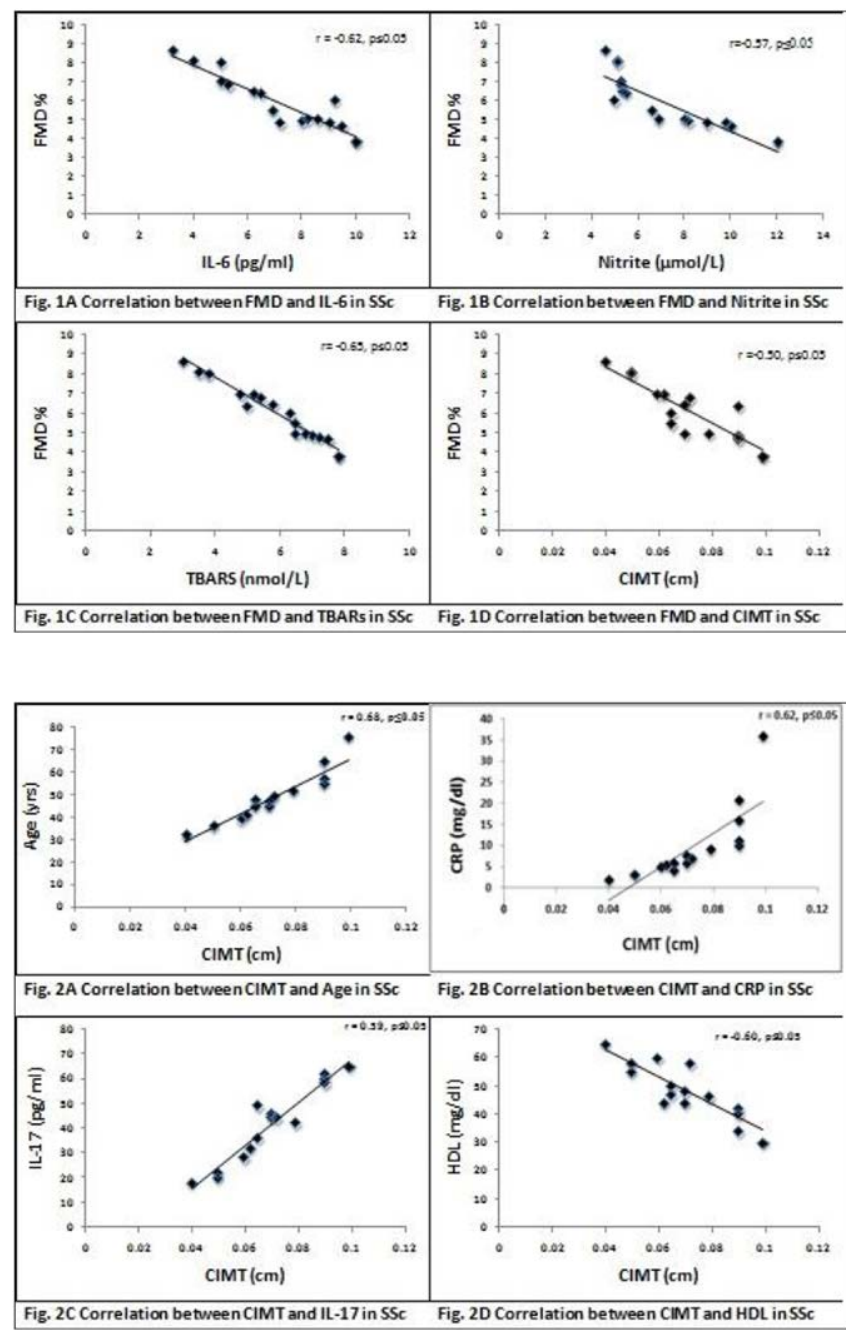

Acknowledgments: None

Disclosure of Interests: None declared

DOI: 10.1136/annrheumdis-2020-eular.5655

\section{AB0578 \\ LONG-TERM TOLERABILITY OF AMINAPHTONE IN A COHORT OF SYSTEMIC SCLEROSIS PATIENTS IN CONCOMITANT STANDARD THERAPY}

E. Gotelli ${ }^{1}$, S. Paolino ${ }^{1}$, F. Goegan ${ }^{1}$, F. Cattelan ${ }^{1}$, M. Patanè ${ }^{1}$, C. Pizzorni ${ }^{1}$, M. Cutolo ${ }^{1}$, A. Sulli ${ }^{1}{ }^{1}$ Research Laboratory and Academic Division of Clinical Rheumatology, Department of Internal Medicine, IRCCS Polyclinic Hospital San Martino, University of Genoa, Genova, Italy 